\title{
Sensory evaluation and consumer acceptability of zinc biofortified rice by farm women in Telangana, India
}

\author{
Amtul Waris*, Chirravuri Naga Neeraja, Mohammed Mohibbe Azam and Battu Jangaiah" \\ ICAR-Indian Institute of Rice Research, Rajendranagar, Hyderabad-500030, TS, India.
}

\section{Article history:}

Received: 12 Dec., 2020

Revised: 5 May, 2021

Accepted: 20 July, 2021

\section{Citation:}

W Amtul, CN Neeraja, MM Azam and B Jangaiah. 2021. Sensory evaluation and consumer acceptability of Zinc biofortified rice by farm women in Telangana, India. Journal of Cereal Research 13(2): 188-196. http:// doi.org/10.25174/2582-2675/2021/111674

\section{*Corresponding author:}

E-mail: amtul.waris@gmail.com

(C) Society for Advancement of Wheat and Barley Research

\begin{abstract}
Most of the Indian diets are typically based on cereals and lack micronutrient-rich vegetables, fruits, and flesh foods. The incorporation of zinc biofortified rice in daily diets can help overcome zinc deficiency. The present study aimed to analyze the consumers' acceptance of zinc biofortified rice as the willingness of consumers to accept it is important for the success of biofortification strategy to combat micronutrient malnutrition. The consumers' acceptance of zinc biofortified rice in terms of its hand feel mouth feel texture, taste, and overall acceptability was determined using the Five-point Hedonic scale. Hand-pounded samples of zinc biofortified rice and control were provided to sixty farm women to evaluate by the Home Use Test protocol. The index of acceptability (IA) was worked out for the acceptance of zinc biofortified rice and was found to be greater than $70 \%$ for all the parameters. The consumers' socio-economic characteristics did not show a significant relationship with the acceptability of zinc biofortified rice except for hand feel texture. Based on the hedonic categorization suggested by Belmes (2019), the overall acceptability of both the zinc biofortified rice and control are in the acceptable category of hedonic rating. Therefore it can be concluded that the zinc biofortified rice variety DRR Dhan 45 is equally acceptable to the consumers as the control rice. The consumers' socio-economic characteristics did not show a significant relationship with the acceptability of zinc biofortified rice. The zinc biofortified rice can be promoted for use in daily diets to help meet the zinc needs of the family and included in the nutrition intervention programs of the country for overcoming micronutrient malnutrition.
\end{abstract}

Keywords: Consumer acceptability, sensory evaluation, zinc biofortified rice, malnutrition, farm women

\section{Introduction}

The micronutrients are very important for various physiological functions and their deficiencies do not lead to physical manifestations as those of macronutrients. Of these micronutrients, deficiencies of zinc and iron are reported to be the most widespread, and their adverse health consequences more severe, , mostly in low and middle-income countries(Gupta et al., 2020). In India, iron and zinc deficiency among children is high ( NFHS4, 2017; and Matthew et al., 2019). Although, zinc and iron both are important micronutrients but this article is focusing on zinc only.

The micronutrient zinc plays an important role in the normal functioning of the body and is integral part of enzyme systems. Mnay important biological functions of zinc include, gene expression, cell division and immunity. (Brown et al., 2004). Adequate dietary intake of zinc helps in normal linear growth of children and has an ameliorating effect on the skin.(Hess and King, 
2009). Zinc deficiency in pregnant women may lead to complications during pregnancy. (Kohn et al., 2000; Donangelo and King, 2012).Zinc palys an important role in linear growth and weight gain (Brown et al., 2002). Zinc deficiency in mothers leads to low supply of zinc to the fetus resulting in premature and low birth weight babies (Hess and King, 2009). the most common feature of zinc deficiency may manifest as diarrhea, respiratory infections, impaired immunity and short staure. (WHO, 2002; Ezzati et al., 2002).

A cross-sectional study in India has reported poor cognitive performance of $45 \%$ of the adolescent girls due to low plasma concentration of zincsignifying the need to incorporate zinc rich foods in the diets. (Kawade 2012). A high prevalence of zinc deficiency due to low dietary intake has been reported in $(64.6 \%)$ in pregnant women and $42 \%$ in among the nulliparous non-pregnant women in India (Pathak et al., 2008; Pathak et al., 2003). The inadequacy of zinc intake in India is very high and devising an intervention program targeting vulnerable populations is essential (Smith et al., 2019).

Inadequate intake of iron and zinc is one of the most significant determinants for the development of their deficiency (de Benoist et al., 2007). Rice is the staple food but in comparison to other foods, it is poor in iron and zinc content (Hemalatha et al., 2007). Elevated zinc requirement, poor absorption and utilization by the body and increased losses, are some of the common factors resulting in zinc deficiency. Dietary factors play an important role in the development of zinc deficiency in developing countries (Gibson and Anderson, 2009). The high phytic acid content in the cereals and cerealbased diets affects their absorption due the formation of zinc-phytic acid complexes in the intestine (Lonnerdal 2000, Davidsson et al., 2004 and Egli et al., 2004). The bioavailability of zinc is greatly influenced by the presence of several other inhibitors (Davidsson et al., 2004), including calcium and polyphenols (Kim et al., 2011). Unlike iron deficiency, due to the non-specific clinical features the diagnosis of zinc deficiency is difficult and the low level of circulating zinc may be used as an indicator.

The recommended dietary allowances for zinc $(\mathrm{mg} / \mathrm{d})$ computed by ICMR are: adult men $12 \mathrm{mg} / \mathrm{d}$, adult women $10 \mathrm{mg} / \mathrm{d}$, pregnant women $12 \mathrm{mg} / \mathrm{d}$, lactating women $12 \mathrm{mg} / \mathrm{d}$, boys aged 13-15 yr $11 \mathrm{mg} / \mathrm{d}$, girls 13-15 yr $11 \mathrm{mg} / \mathrm{d}$, and children 7-9 yr $8 \mathrm{mg} / \mathrm{d}$ (NIN, 2009).The zinc requirements are high during pregnancy and rapid physiological growth as in children and the inadequate intake leads to higher deficiency.

The pharmaceutical approach of supplementation, the industrial approach of food fortification, and agricultural approaches of dietary diversification and bio-fortification have been advocated as some of the strategies to address micronutrient deficiencies. Crop bio-fortification is increasingly being recognized as a cost-effective and sustainable approach.

Rice is a major staple food consumed widely by the poor population and serves as an ideal crop for fortification. Rice consumption in India was estimated to be 102 million tonnes in 2019-20 and it is expected to increase to 108 million tonnes in 2020-21 (Reidy 2020). Therefore, in the bio-fortification program (Nestel et al., 2006; Pfeiffer \& McClafferty, 2007), a major focus is to breed rice containing more $\mathrm{Zn}$. In this direction, the Indian Institute of Rice Research, Hyderabad, has made considerable efforts and developed three bio-fortified high zinc rice varieties, namely, DRR Dhan 45, DRR Dhan 48 and DRR Dhan 49 with a zinc concentration of $22.6 \mathrm{ppm}, 24$ ppm, and $25.2 \mathrm{ppm}$ respectively in polished grain and all are of medium duration (125-130 days) with an average grain yield of 50q/ha (Yadava et al., 2020). Some more varieties like Zinco Rice, CR Dhan 311, and CR Dhan 315 have been developed and released by other research institutes (Yadava et al., 2020).

Including biofortified varieties in daily diets may help to overcome zinc deficiencies in vulnerable populations viz, women and children (Woods et al., 2020). The nutritional intervention program of the Indian Government, Poshan Abhiyan (India.gov.in) can benefit from the biofortified crops in its efforts to reduce undernutrition and stunting as demonstrated in other regions of the world as a simple and cost-effective strategy (Reddy, 2020).

The willingness of consumers and producers to accept new crop varieties will determine whether biofortification can be successfully implemented. The acceptance of biofortified varieties by consumers is an important aspect of the biofortification program (Saltzman et al., 2013). Consumer acceptance of new products is evaluated primarily by three methods, viz. laboratory tests, central location tests (CLT) and home use tests (HUT) (Meilgaard 
et al., 2007). In HUT, the consumer prepares the food in his/her own way and consumes the food in its own environment. In-home use test the consumers can assess the product as per their expectations (Lawless and Heymann, 2010).

The objective of the present study was to determine consumers' acceptance of zinc biofortified rice variety DRR Dhan 45 through sensory evaluation in home-use testing. The rice variety DRR Dhan 45 is developed by the Indian Institute of Rice Research (IIRR) and released in 2016. It is the first among the high zinc rice varieties notified at the national level and has an overall mean zinc content of $22.6 \mathrm{ppm}$ (Yadav et al., 2020). This is a semi-dwarf, medium duration (125 days) variety with long slender grain and non-lodging type. It is moderately resistant to blast, sheath rot, and rice tungro virus. It is released for the states of Tamil Nadu, Andhra Pradesh, and Karnataka and has good cooking quality with desirable amylose content (20.7\%).

\section{Materials \& Methods}

The study was conducted in Nalgonda district of Telangana State, India, which has a high prevalence of stunting (28.3\%), underweight (31.3\%), wasting (21.2\%) and anemia $(69.2 \%)$ among the child population (Kim et al., 2019) and high levels of anemia among women, 56.2\% (NFHS-4, 2017). Convenience sampling was used in the study and ten farm women beneficiaries of the outreach programs of the Indian Institute of Rice Research (IIRR) were selected randomly from each of the six tribal hamlets of Deverkonda Mandal of Nalgonda district of Telangana. Thus the total sample size was 60 farm women. An information session was conducted in the local language with the farm women to obtain their verbal consent. The farm women were provided $500 \mathrm{gm}$ each of hand-pounded rice of the high zinc variety DRR DHAN 45 (Zinc, 22.6 ppm) and check variety (Zinc, $16.7 \mathrm{ppm}$ ) (Yadav et al., 2020).

The cooking protocol for both biofortified and control variety was typical of how the rice is cooked by the farm women. The farm women rated the zinc biofortified rice and control with respect to hand feel texture, mouthfeel texture, taste, and overall acceptability. A hedonic test was used on a 5-point hedonic scale (1-very poor, 2-poor, 3 - neither poor nor good, 4-good, and 5-very good). The intervals between each score are not the same and also a product that is rated 4 is not necessarily two times as much liked more than a product rated 2. The consumers' scores are measured on an ordered categorical scale and need to be analysed accordingly (Coe, 2002).

\subsection{Sensory evaluation testing using modified home use testing (HUT)}

Sensory characteristics of zinc biofortified rice (DRR Dhan 45) and control (BPT-5204) were determined using a home use test. At the time of the present study, only small quantity of paddy grain of zinc biofortified rice was available and it could not be commercially milled for consumer acceptability study. Therefore, for home use test, hand-pounded samples of both zinc biofortified and control rice were provided to 60 farm women which is the minimum number of consumers required for a consumer acceptability study (Hough et al., 2006; ISO 8587:2006; and Stone and Sidel, 2004) and hedonic scaling test (Gacula and Rutenbeck, 2006).

The hedonic rating as suggested by Belmes (2019) on a five-point scale was used for the categorization of sensory attributes of both zinc biofortified rice and control. The associated ranges of scores with the level of acceptability were rated as follows: 4.50-5.00 as Highly Acceptable (HA); 3.50-4.49 as Acceptable (A); 2.50-3.49 as Moderately Acceptable (MA); 1.50-2.49 as Slightly Acceptable (SA) and 1.00-1.49 as Not Acceptable (NA). The independent Student's $t$ test was used to test the difference in mean scores between the two types of rice.

\subsection{Index of acceptability (IA)}

The index of acceptability (IA) was calculated using the following equation (Fernandes and Salas-Mellado (2017):

IA $(\%)=($ Score $\mathrm{x} 100) / 5$

Where, the score represented acceptability reported by the farm women based on the 5-point hedonic scale.

\section{Results and Discussion}

\subsection{Socio-demographic characteristics of the consumers}

The socio-demographic characteristics of the respondents indicated that, majority of the respondents (66.7\%) belonged to 31-50 age group followed by the 21-30 years age (20\%) and about 13\% were in the 51-60 years age group. A very high percentage $(75 \%)$ of the respondents were illiterate followed by 15 percent educated to the primary level schooling followed by nearly seven percent 
educated up to the secondary level and only three percent belonged to the higher secondary education category. Most of the farm women (36.7\%) were having 11-20 years of farming experience followed by $35 \%$ having $1-10$ years, $23.3 \%$ of the respondents had 21-30 years experience and only a very small percentage (5\%) had a farming experience in the range of 31- 40 years. It was recorded that 57 percent of the farm women were members of some organizations and 43 percent of them were not having membership in any organization.

\subsection{Consumer acceptability of sensory characteristics of zinc biofortified rice and control}

The mean sensory scores of zinc biofortified rice and control have been presented in Table 1 . None of the farm women rated the hand feel texture as very poor or very good. An equal percentage (37\%) of respondents rated it in the 'poor' and 'neither poor nor good' category. Only $25 \%$ of the consumers rated it as 'good'. The mouthfeel texture was rated as 'good' by $56.7 \%$ of the farm women followed by 'neither poor nor good' by $30 \%$. An equal percent of farm women $(6.7 \%)$ rated it as 'poor' and 'very good'. The taste of biofortified cooked rice was rated as 'good' by $50 \%$ of the farm women and $30 \%$ rated it as 'very good' followed by 'poor' $(20 \%)$ and $11.7 \%$ rated it as 'neither poor nor good' in taste. The overall acceptability of zinc biofortified rice was rated as 'good' by $56.6 \%$ of the consumers followed by $25 \%$ showing a neutral attitude of 'neither poor nor good', 13.3\% rated it as 'very good' and $5 \%$ rated it as 'poor'.

Similarly, for control, none of the farm women rated the hand feel texture as 'very poor', but $5 \%$ rated it as 'poor'. About half of the respondents (51.6\%) rated it as 'good' followed by 'neither poor nor good' (26.7\%). It was rated as 'very good' by $16.7 \%$ of the farm women. The mouth feel texture was rated as 'good' and 'very good' by $53.3 \%$ and $25 \%$ of the farm women, respectively. None of the farm women rated it as 'very poor' or 'poor'. Taste was rated as 'very good' by $61.7 \%$, 'good' by $28.3 \%$, and 'neither poor nor good' by $10 \%$ of the farm women. The overall acceptability of control was rated as 'very good' by $41.7 \%$, 'good' by $38.3 \%$, and $20 \%$ of farm women were showing a neutral attitude of 'neither poor nor good'.

A study from Cuba indicated an overall liking for zinc and iron enhanced rice variety (Padron et al., 2011). While another study in Nicaragua indicated an overall liking for the control in comparison to nutritionally enriched rice (Montecinos et al., 2011). Two biofortified rice varieties and control were equally accepted by consumers in a study in Bolivia (Woods et al., 2020). In a Colombian study, the biofortified variety had a higher overall acceptance compared to the locally consumed variety (Woods et al., 2020). A study among rice consumers in Bangladesh reported the acceptability of smell, colour, and taste of fortified rice by the majority of the participants (Chakravorty and Akhter, 2014). Moretti et al. (2005), and Beinner (2010), reported that fortified rice was acceptable to the panelists. Biofortified rice as a good source of bioavailable zinc as compared to rice postharvest fortified has been reported by Marica Brnić et al. (2016). Recommending the appropriate cooking method in retaining micronutrient content in cooked rice and educating the homemakers too plays a vital role in the acceptance of fortified rice (Azam et al., 2021).

The results (Table 1) based on the categorization by Belmes (2019) indicate that the hand feel texture of zinc biofortified rice was moderately acceptable while that of control is acceptable. As for mouth feel texture both the zinc biofortified rice and control is acceptable. The taste of both zinc biofortified rice and control are in the acceptable category. Similarly, the overall acceptability of both the zinc biofortified rice and control were in the acceptable category of hedonic rating. However, both zinc biofortified rice and control were not rated in the highly acceptable category. The plausible reason could be that samples of both zinc biofortified rice and control were hand-pound and most of the consumers are accustomed to eat highly uniform and polished white rice. Therefore it can be concluded that the zinc biofortified rice variety DRR Dhan 45 is equally acceptable to the consumers as the control rice. Rai et al. (2019) reported no differences in hedonic scores for nonfortified rice and rice blended with fortified rice kernels and concluded that the acceptability of fortified rice primarily depends on the palatability of the fortified rice. Similarly, no difference in mean hedonic scores for rice fortified with ferric pyrophosphate and non-fortified rice was reported by Radhika et al. (2011). No significant difference in overall acceptability between the normal and iron-fortified rice products was reported by Sarkar et al. (2015). 
Sensory evaluation and consumer acceptability of Zinc biofortified rice by farm women in Telangana, India

Table 1: Mean sensory scores of zinc biofortified rice and control (n-60)

\begin{tabular}{lllll}
\hline \multirow{2}{*}{ Parameters } & \multicolumn{2}{l}{ Biofortified rice $($ DRR Dhan 45) } & \multicolumn{2}{l}{ Control (BPT-5204) } \\
\cline { 2 - 4 } & Sensory Score & Acceptability level & Sensory Score & Acceptability level \\
\hline Hand feel texture & $3.45 \pm 0.565^{\mathrm{a}}$ & Moderately Acceptable & $3.98 \pm 0.724^{\mathrm{b}}$ & Acceptable \\
Mouth feel texture & $3.63 \pm 0.713^{\mathrm{b}}$ & Acceptable & $4.08 \pm 0.590^{\mathrm{b}}$ & Acceptable \\
Taste & $4.02 \pm 0.873^{\mathrm{b}}$ & Acceptable & $4.38 \pm 0.613^{\mathrm{b}}$ & Acceptable \\
Overall acceptability & $3.75 \pm 0.750^{\mathrm{b}}$ & Acceptable & $4.2 \pm 0.567^{\mathrm{b}}$ & Acceptable \\
\hline
\end{tabular}

All values are means \pm SDs. Values in the same row having same alphabet were not significantly different by independent Student's $t$ test ( $<<.050$ ).

The calculated Index of Acceptability (IA) of zinc biofortified rice (DRR Dhan 45) and control has been shown in Table 2 and Figure 1. It shows that the IA was more than $70 \%$ for all the parameters for both zinc biofortified rice and control except for the hand feel texture of zinc biofortified rice that obtained a slightly lower score on acceptability (69\%). According to Spehar and Santos (2002) for a product to be considered acceptable in terms of its sensory properties, it must obtain a minimum score of $70 \%$. Thus it can be concluded that the sensory attributes of zinc biofortified rice are acceptable to the consumers and they may be motivated to include it in their daily diets. The supply-side issues may be addressed to ensure the availability of zinc biofortified rice in the local markets. Consequently, it may be provided under the various nutritional intervention programs especially for children and women from the vulnerable population.

Table 2: Index of Acceptability for zinc biofortified rice and control

\begin{tabular}{ccc}
\hline \multirow{2}{*}{ Parameters } & Zinc biofortified rice (DRR Dhan 45) & Control (BPT-5204) \\
\cline { 2 - 3 } & Index of Acceptability & Index of Acceptability \\
\hline Hand feel texture & 69.0 & 79.6 \\
Mouthfeel texture & 72.6 & 81.6 \\
Taste & 80.2 & 87.6 \\
Overall acceptability & 76.5 & 84.0 \\
\hline
\end{tabular}

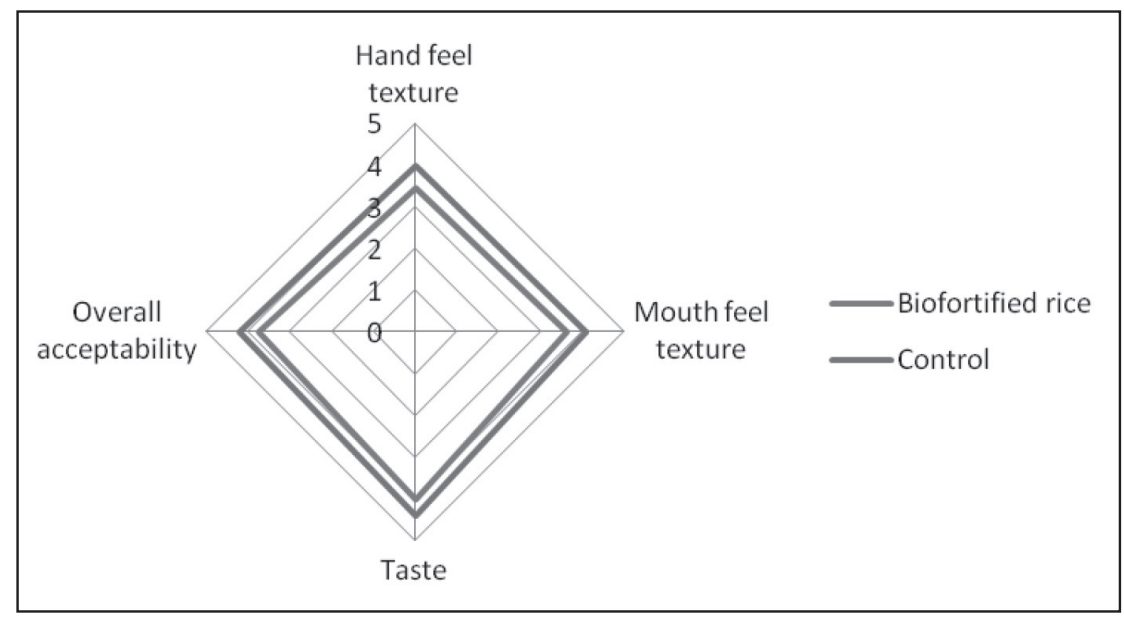

Figure 1: Consumer acceptability scores on a 5 - point hedonic scale

(Scale: 1 very poor; 2- poor; 3- neither poor nor good; 4- good; 5- very good) 


\subsection{Relationship between socio-economic characteristics and consumer acceptability of zinc biofortified rice}

Attempts were made to find the relationship between the personal characteristics of farm women and the acceptability of zinc biofortified rice through the determination of Pearson's correlation coefficient (Table 3). It was found that none of the personal attributes of the farm women indicated a statistically significant relationship. The interaction coefficient for education, membership in organizations and farming experience though positive is insignificant. Whereas, age, family members and farm size have shown negative and insignificant relationship. Thus, it can be concluded that zinc biofortified rice would be accepted irrespective of the age, educational status, family size, farm size, membership status and farming experience of farm women. In a similar study on acceptability of biofortified products, Etumnu (2016) found that consumers' socio-economic characteristics did not have a significant effect on acceptance of biofortified orange flesh sweet potato in Sub-Saharan Africa.

Table 3: Relationships between socio economic characteristics and zinc biofortified rice acceptability

\begin{tabular}{|c|c|c|}
\hline \multicolumn{3}{|c|}{ Acceptability of Zinc biofortified rice } \\
\hline \multirow{3}{*}{ Age } & Pearson Correlation & -0.079 \\
\hline & Sig. (2-tailed) & 0.548 \\
\hline & $\mathrm{N}$ & 60 \\
\hline \multirow{3}{*}{ Education } & Pearson Correlation & 0.042 \\
\hline & Sig. (2-tailed) & 0.747 \\
\hline & $\mathrm{N}$ & 60 \\
\hline \multirow{3}{*}{ Family Members } & Pearson Correlation & -0.138 \\
\hline & Sig. (2-tailed) & 0.292 \\
\hline & $\mathrm{N}$ & 60 \\
\hline \multirow{3}{*}{ Membership } & Pearson Correlation & 0.132 \\
\hline & Sig. (2-tailed) & 0.315 \\
\hline & $\mathrm{N}$ & 60 \\
\hline \multirow{3}{*}{ Farm Size } & Pearson Correlation & -0.066 \\
\hline & Sig. (2-tailed) & 0.619 \\
\hline & $\mathrm{N}$ & 60 \\
\hline \multirow{3}{*}{ Experience } & Pearson Correlation & 0.064 \\
\hline & Sig. (2-tailed) & 0.627 \\
\hline & $\mathrm{N}$ & 60 \\
\hline
\end{tabular}

\section{Conclusion}

Consumer acceptance of biofortified rice is an important criterion for its incorporation in the daily diets of families. Zinc biofortified rice, DRR Dhan 45 was acceptable to the consumers and the index of acceptability was greater than $70 \%$. Moreover, based on hedonic scoring both the zinc biofortified rice and control are in the acceptable category. The socio-demographic characteristics of the consumers did not show a statistically significant relationship with the acceptability of zinc biofortified rice and it can be concluded that its acceptance is independent of the personal and social attributes of the consumers. Further studies on consumer acceptability may be undertaken with polished rice with a larger sample both in urban and rural areas and also with different age groups of children as consumers. Based on the acceptability of zinc biofortified rice it is recommended that it may be included in the supplementary feeding programs for children and nutritional intervention programs for women to overcome micronutrient malnutrition. 
Sensory evaluation and consumer acceptability of Zinc biofortified rice by farm women in Telangana, India

\section{Compliance with ethical standards}

NA

\section{Conflict of Interest}

Authors declare that they have no conflict of interest

\section{Authors' contribution}

Conceptualization of research and designing of experiments (AW, CNN), Conduction of experiment (AW, MMA, BJ), Preparation of manuscript (AW, CNN).

\section{References}

1. Azam MM, S Padmavathi, RA Fiyaz, A Waris, KT Ramya and C N Neeraja. 2021. Effect of different cooking methods on loss of iron and zinc micronutrients in fortified and non-fortified rice. Saudi Journal of Biological Sciences 28(3): 2886-2894.

2. Beinner MA, ADN Soares, ALA Barros and MAM Monteiro. 2010. Sensory evaluation of rice fortified with iron. Food Science and Technology 30(2): 516-519.

3. Belmes NJ. 2019. BATUAN (Garciniabinucao) fruit preservation. 1st UPY International Conference on Applied Science and Education 2018 Journal of Physics: Conference Series 1254 (2019) 012030 IOP Publishing doi:10.1088/1742-6596/1254/1/012030.

4. Brown KH, JA Rivera, Z Bhutta, RS Gibson, JC King, B Lönnerdal, MT Ruel, B Sandtröm, E Wasantwisut, C Hotz, DL deRomaña and JM Peerson. 2004. International Zinc Nutrition Consultative Group (IZiNCG) technical document \# 1 . Assessment of the risk of zinc deficiency in populations and options for its control. Food and Nutrition Bulletin 25: S99-S203.

5. Brown KH, JM Peerson, J Rivera and LH Allen. 2002. Effect of supplemental zinc on the growth and serum zinc concentrations of prepubertal children: a metaanalysis of randomized controlled trials. American Journal of Clinical Nutrition 75: 1062-1071.

6. Chakraborty B and F Akter. 2014. Acceptability of fortified rice by participants of Government social safety net programmes. Dhaka, Bangladesh.

7. Coe R. 2002. Analyzing ranking and rating data from participatory on-farm trials. In: Bellon, M. R. \& Reeves, J. Quantitative analysis of data from participatory methods in plant breeding. Mexico, DF: CIMMYT
8. Davidsson L, EE Ziegler, P Kastenmayer, Pvan Dael and D Barclay. 2004. Dephytinisation of soyabean protein isolate with low native phytic acid content has limited impact on mineral and trace element absorption in healthy infants. British Journal of Nutrition 91: 287-94.

9. de Benoist B, I Darnton-Hill, L Davidsson, O Fontaine and C Hotz. 2007. Conclusions of the Joint WHO/UNICEF/ IAEA Interagency Meeting on Zinc Status Indicators. Food and Nutrition Bulletin 28 (Suppl 3): S480-S484.

10. Donangelo CM and JC King. 2012. Maternal zinc intakes and homeostatic adjustments during pregnancy and lactation. Nutrients 4: 782-98.

11. Egli I, L Davidsson, C Zeder, T Walczyk, and R Hurrell. 2004. Dephytinization of a complementary food based on wheat and soy increases zinc, but not copper, apparent absorption in adults. Journal of Nutrition 134: 1077- 1080.

12. Etumnu C. 2016. Selected Paper prepared for presentation at the 2016 Agricultural \& Applied Economics Association Annual Meeting Boston, Massachusetts, July 31-August 2.

13. Ezzati M, AD Lopez, A Rodgers, S Vander Hoorn, and CJ Murray. 2002. Comparative Risk Assessment Collaborating Group. Selected major risk factors and global and regional burden of disease. Lancet 360: 1347-60.

14. Fernandes SS and MM Salas-Mellado. 2017. Addition of chia seed mucilage for reduction of fat content in bread and cakes. Food Chemistry 227:237-244.

15. Gacula MJ and S Rutenbeck. 2006. Sample size in consumer test and descriptive analysis. Journal of Sensory Studies 21(2): 129-145.

16. Gibson RS and VP Anderson. 2009. A review of interventions based on dietary diversification or modification strategies with the potential to enhance intakes of total and absorbable zinc. Food and Nutrition Bulletin 30 (Suppl 1): S108-S143.

17. Gupta S, AKM Brazier and NM Lowe. 2020. Zinc deficiency in low and middle income countries: prevalence and approaches for mitigation. Journal of Human Nutrition and Dietetics 33:623-644 
18. Hemalatha S, K Platel and K Srinivasan. 2007. Zinc and iron contents and their bioaccessibility in cereals and pulses consumed in India. Food Chemistry 102:1328-1336.

19. Hess SY and JC King. 2009. Effects of maternal zinc supplementation on pregnancy and lactation outcomes. Food and Nutrition Bulletin 30(Suppl 1): S60-S78.

20. Hough G, I Wakeling, A Mucci, IVE Chambers, IM Gallardo and LR Alves. 2006. Number of consumers necessary for sensory acceptability tests. Food quality and preference 17(6):522-6

21. India. gov. in. https: //www.india.gov.in /spotlight/ poshan-abhiyaan-pms-overarching-scheme-holisticnourishment

22. ISO 8587:2006. 2006. Sensory analysis methodology ranking https://www.iso.org/standard/36172.html

23. Kawade R. 2012. Zinc status and its association with the health of adolescents: a review of studies in India. Glob Health Action 5:7353.

24. Kim EY, TK Pai and O Han. 2011. Effect of bioactive dietary polyphenols on zinc transport across the intestinal Caco-2 Cell monolayers. Journal of Agricultural and Food Chemistry 59: 3606-3612.

25. Kim R, A Swaminathan, R Kumar, Y Xu, JC Blossom, R Venkataramanan, A Kumar, J William, and SV Subramanian. 2019. Estimating the burden of child malnutrition across parliamentary constituencies in India: A methodological comparison, SSM Population Health 7, 100375 ISSN 2352-8273. https://doi.org/10.1016/j.ssmph.2019.100375.

26. 26. King JC, KH Brown, RS Gibson, NF Krebs, NM Lowe, JH Siekmann, and DJ Raiten. 2016. Biomarkers of nutrition for Development (BOND)Zinc Review. Journal of Nutrition 146(4): 858S-885S

27. Kohn S, D Kohn and D Schiller. 2000. Effect of zinc supplementation on epidermal Langerhans' cells of elderly Patients with decubital ulcers. Journal of Dermatology 27: 258-63.

28. Lawless HT and H Heymann. 2010. Sensory evaluation of food: principles and practices. Springer Science \& Business Media.
29. Lönnerdal B. (2000). Dietary factors influencing zinc absorption. Journal of Nutrition 130 (Suppl 5S): 1378S-1783S.

30. Marica Brnić, R Wegmüller, A Melse-Boonstra, T Stomph, C Zeder, FM Tay, and RF Hurrell. 2016. Zinc Absorption by adults is similar from intrinsically labeled zinc-biofortified rice and from rice fortified with labeled zinc sulfate, Journal of Nutrition 146 (1): 76-80.

31. Matthew RS, DF Ruth, A Chhatre, S Ghosh-Jerath, and SM Samuel. 2019. Inadequate zinc intake in India: Past, Present, and Future. Food and Nutrition Bulletin 40(1): 26-40

32. Meilgaard M, G Civille, and T Carr 2007. Sensory evaluation techniques. $4^{\text {th }}$ ed. New York: CRC Press.

33. Montecinos KLG, JAG Godoy, PMC Centeno, and H Pachón. 2011. Sensory evaluation of rice (Oryza sativa) variety Azucena in the Autonomous Region of the North Atlantic in Nicaragua. Perspect. Human Nutrition 13(2): 135-146.

34. Moretti D, TC Lee, MB Zimmermann, J Nuessli, and RF Hurrell. 2005. Development and evaluation of iron-fortified extruded rice grains. Journal of food science 70(5): S330-S336.

35. Nestel P, HE Bouis, JV Meenakshi, and W Pfeiffer. 2006. Biofortification of staple food crops. Journal of Nutrition 136: 1064-1067

36. NFHS-4. 2017. National Family Health Survey (NFHS-4), 2015-16. International Institute for Population Sciences (IIPS) and ICF, Mumbai, India. http://rchiips.org/NFHS/index.shtml.

37. NIN. 2009. Nutrient Requirements and Recommended Dietary Allowances for Indians ( A Report of the Expert Group of the ICMR). National Institute of Nutrition, Indian Council of Medical Research, Hyderabad, 2009.

38. Padrón VP, ES Crestelo, RA Caraballo, H Pachón and CP Martínez. 2011. Preference and acceptability of the IACuba 30 rice variety with high iron and zinc content by pregnant women in Cuba. Perspectivas en Nutrición Humana 13: 123-134.

39. Pathak P, U Kapil, SK Kapoor, SN Dwivedi, and R Singh. 2003. Magnitude of zinc deficiency 
among nulliparous nonpregnant women in a rural community of Haryana State, India. Food and Nutrition Bulletin 24: 368-371.

40. Pathak P, U Kapil, SN Dwivedi and R Singh. 2008. Serum zinc levels amongst pregnant women in a rural block of Haryana State, India. Asia Pacific Journal of Clinical Nutrition 17:276-279.

41. Pfeiffer WH and B Mcclafferty. 2007. Harvest Plus: Breeding Crops for Better Nutrition International Plant Breeding Symposium • December 2007, S-89105.

42. Radhika MS, KM Nair, RH Kumar, MV Rao, P Ravinder, CG Reddy and GNV Brahmam. 2011. Micronized ferric pyrophosphate supplied through extruded rice kernels improves body iron stores in children: a double-blind, randomized, placebocontrolled midday meal feeding trial in Indian schoolchildren. American Journal of Clinical Nutrition 94(5): 1202-1210.

43. Rai A, MR Maharjan, FHA Harris, PK Chhetri, PC Wasti, and NM Saville. 2019. Consumption of rice, acceptability and sensory qualities of fortified rice amongst consumers of social safety net rice in Nepal. PLOS ONE 14 (10): e0222903.

44. Reddy AA. 2020. Rice with zinc, wheat with protein - Bio-fortified crops can fight India's hidden hunger. https://theprint.in/opinion/rice-with-zinc-wheatwith-protein-biofortified-crops-fight-india-hiddenhunger/533482/

45. Reidy S. 2020. India's wheat, rice production continue to reach record highs world-grain.com/ articles/13532-indias-wheat-rice-production-continueto-reach-record.
46. Saltzman A, E Birol, HE Bouis, E Boy, FF de Moura, Y Islam and WH Pfeiffer. 2013. Biofortification: progress toward a more nourishing future. Global Food Security 2(1): 9-17

47. Sarkar S, A Kuna, MM Azam, M Sowmya and ES Kumar. 2015. Sensory and consumer evaluation of iron fortified rice. Oryza 52 (3): 231-236.

48. Smith MR, R DeFries, A Chhatre, S Ghosh-Jerath and SS Myers. 2019. Inadequate zinc intake in India: past, present, and future. Food and Nutrition Bulletin 40(1): 26-40.

49. Spehar CR and RLB Santos. 2002. Quinoa BRS Piabiru: Quinoa BRS Piabiru: alternative for diversification of cropping systems. Pesquisa Agropecuária Brasileira 37(6): 809-893.

50. Stone H, and JL Sidel. 2004. Sensory evaluation practices. San Diego: Elsevier Academic Press

51. WHO 2002. World Health Report 2002: reducing risks, promoting healthy life. Geneva: World Health Organization, 7-14.

52. Woods BJ, CS Gallego, EF Talsma and DA'lvarez. 2020. The acceptance of zinc biofortified rice in Latin America: A consumer sensory study and grain quality characterization. PLOS ONE 15(11): e0242202.

53. Yadava DK, PR Choudhury, F Hossain, D Kumar, and T Mohapatra. 2020. Biofortified Varieties: Sustainable Way to Alleviate Malnutrition (Third Edition). Indian Council of Agricultural Research, New Delhi. 86p. 